To the Editors:

\title{
Private health insurance profits: the need to take a closer look
}

\author{
Ceylon Medical Journal 2011; 56: 136-138
}

Sri Lanka has invested in a free health care service and a free education system even before independence. The free health care service extends from preventive to curative sectors encompassing even tertiary health care throughout the whole country. The free health care system has become a major burden to the country over the years with development of new technologies and the increase in people's aspirations and needs. During the last two decades, a number of reports have addressed this issue [1].

One method of financing health care is through health insurance, a method of risk sharing focussing mainly on reducing the economic burden during a catastrophic illness. Risk-sharing through insurance is most worthwhile when the event insured against is largely unpredictable, infrequent, costly, unwanted, unplanned and uncontrollable by the insured.

Voluntary private indemnity health insurance is provided through employers, mutual societies, cooperatives or directly by companies; these generally cover hospital and physician services, but the benefits are limited or non-existent for preventive services, primary care, or outpatient drugs. In Sri Lanka, private health insurance is the most rapidly increasing source of health care financing which has increased from $<1 \%$ in 1990 to $3 \%$ in 2006 .

The purpose of this investigation is to describe some important characteristics of private health insurance schemes available to consumers in the country. Three insurance companies were contacted and details of health insurance plans were obtained. The benefits of some health insurance plans currently available are given in Table 1.

The benefits are dependent on the type of plan and there is upper limit for the number of days an enrolee can make claims. All plans have a benefit for patients admitted to government hospitals in which services are provided free of charge. In Sri Lanka, the share of the public sector for inpatient care is $72 \%$; and for outpatient care it is $35 \%$. In 2006, except in Malaysia (26.2\%) and Hong Kong $(16.5 \%)$, private health insurance accounted for less than $10 \%$ of the total health expenditure for countries in the South and Southeast Asian region [2].
Based on plans of company 1 (Table 1) for the private sector, assuming if only room charges are accounted for, a patient will be paid upto 40 days per event. If the same patient stays in a government hospital, he has benefits for 50 days. In plan 1 of company 1 , the benefits for staying 50 days in a government hospital is Rs $250.00 \times 50$ which is Rs $12,500.00$ as compared to Rs $40,000.00$ for staying 40 days in a private hospital. Likewise, in plan 2 of company 1 , the benefits for staying 50 days in a government hospital is Rs 20,000.00 as compared to Rs 64,000.00 for staying 40 days in a private hospital. Likewise, in plan 3 of company 1 , the benefits for staying 50 days in a government hospital is Rs $25,000.00$ as compared to Rs $80,000.00$ for staying 40 days in a private hospital.

In the plans of company 2, the number of days of benefits for hospitalisation per event is variable. In plan 5 of company 2, the benefits for staying 15 days in a government hospital is Rs $1,000.00 \times 15$ which is Rs $15,000.00$ as compared to Rs $120,000.00$ for staying 40 days in a private hospital. Similar benefits are provided by company 3 in all its plans.

It is seen that insurance companies can have profits ranging from Rs. 37,500.00 to Rs 105,000.00 by promoting patients to seek treatment in government hospitals as opposed to seeking care in private hospitals. In other words, the benefit given to patients seeking treatment from government hospitals is like being paid to be sick.

Providing two methods of benefits for hospitalisation in public and private sector hospitals is not only defrauding the enrolee but also morally unacceptable. These health insurance plans and insurance companies in a sense are avoiding their corporate social responsibilities by further burdening the public sector health care services. We strongly recommend that the government should bring legislation, so that, when a patient with health insurance is admitted to a government hospital, it should be able to obtain the full benefits that the patient would obtain if(s) he were admitted to a private hospital. This is one way of recovering public health expenditure, however small that component may be, that could be utilised for upgrading the services provided by the government hospitals at no extra burden to the consumer. 


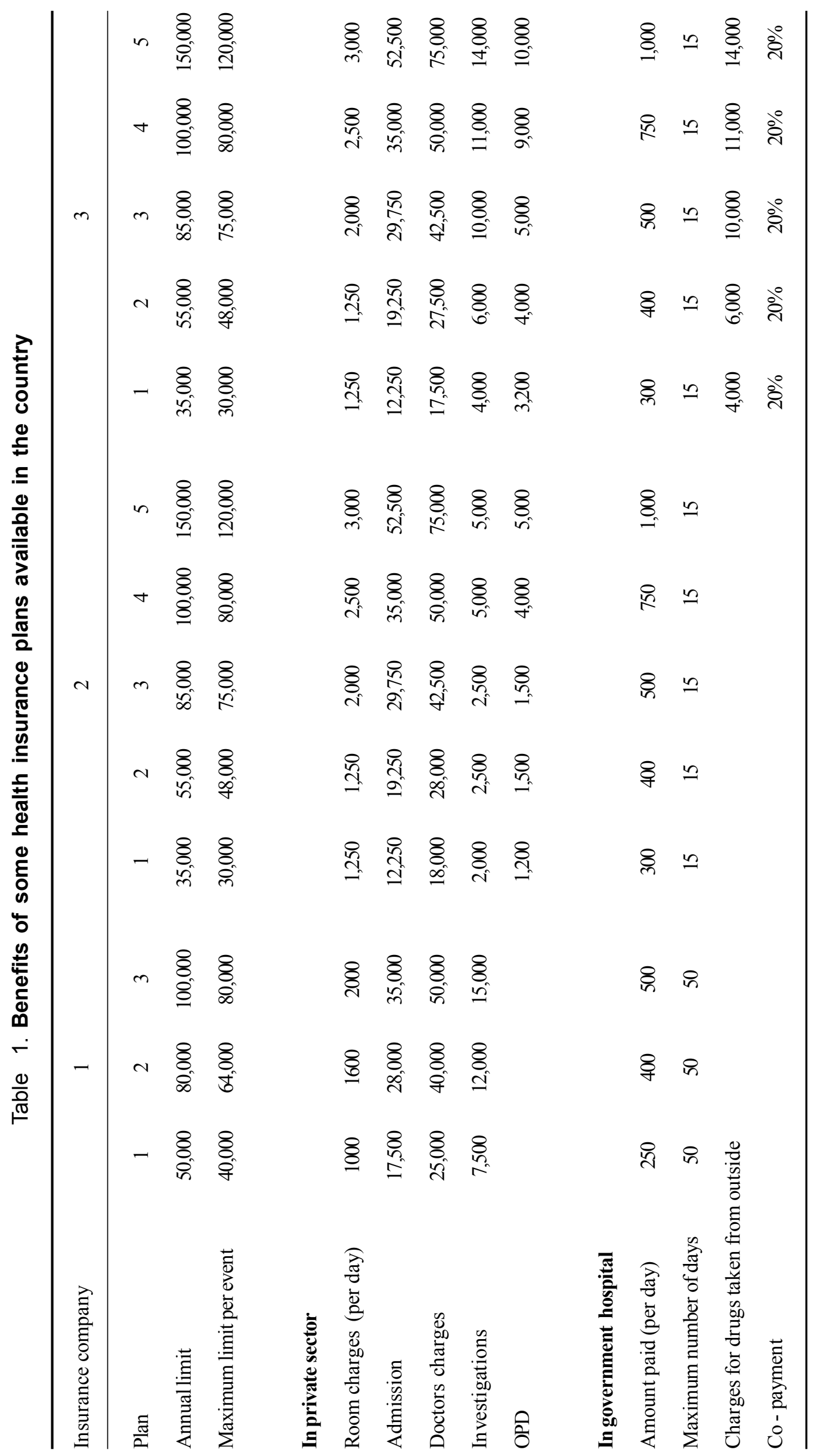




\section{References}

1. Rannan-Eliya RP. Strengthening of Health Financing in Partner Developing Countries. In: Task Force on Global Action for Health Systems Strengthening. Global Action for Health System Strengthening: Policy Recommendation to the G8.
Tokyo: Japan Center for International Exchange, 2009: 59-90.

2. Fernando T, Rannan-Eliya RP, Jayasundara JMH. (2009) Sri Lanka Health Accounts: National Health Expenditures 1990-2006. Health Expenditure Series No. 1. Colombo, Institute for Health Policy.

\section{H S M Peiris ${ }^{1}$, A R Wickremasinghe ${ }^{1}, \mathrm{~K}$ Balasubramanium ${ }^{2}$}

${ }^{1}$ Faculty of Medicine, University of Kelaniya, Ragama, Sri Lanka, ${ }^{2}$ Health Action International Asia Pacific, Colombo, Sri Lanka.

Correspondence: ARW, e-mail: <arwicks@sItnet.lk>. Received 10 October 2010 and revised version accepted 26 February 2011. Competing interests: none declared. 